\title{
BEHAVIORAL DETERMINANTS OF CORRUPTION. A CROSS-COUNTRY SURVEY
}

\section{Professor Sorin Nicolae Borlea, PhD Habil.}

„Vasile Goldiș” Western University of Arad, Romania

E-mail: snborlea@yahoo.com

\author{
Professor Monica Violeta Achim*, PhD Habil. \\ „Babeș-Bolyai ” University, Cluj-Napoca, Romania \\ E-mail: monica.achim@econ.ubbcluj.ro
}

\author{
Alexandra Ioana Daniela Rus, PhD. Candidate \\ „Babeș-Bolyai” University, Cluj-Napoca, Romania \\ E-mail: rusalexandra04@yahoo.com
}

\section{(Received: November 2018; Accepted: February 2019; Published: March 2019)}

\begin{abstract}
This research comes to empirical investigate whether the country's levels of corruption may be explained by some behavioral factors such as culture, tax morale, trust, religion or happiness. For this purpose, a cross-countries survey of 148 countries is used. The findings document that power distance, trust in legal system, happiness and religion are the most important behavioral determinants of the corruption, explaining about $50 \%$ from the level of corruption around the world. A higher power distance, a lower level of trust in legal system, a lower level of happiness (measured by subjective well-being) and a higher level of religiosity conduct to a higher level of corruption. The findings are important for the policy-makers in order to include the non-economic factors in the analysis of corruption behavior of the people belong to a country, and thus to adopt the most appropriate decisions to fight against this phenomenon.
\end{abstract}

Keywords: corruption, culture, tax morale, trust, religion, happiness

JEL Codes: D73, E62, H26

\section{Introduction}

Despite all efforts of the governments for fighting against corruption, this phenomenon increases around the world's countries (Bock \& Byrne, 2017). In order to combat this, the governments need to switch the attention from the

*Corresponding author: Monica Violeta Achim. E-mail: monica.achim@econ.ubbcluj.ro

$S$ sciendo Studia Universitatis "Vasile Goldis" Arad. Economics Series Vol 29 Issue 1/2019

ISSN: 1584-2339; (online) ISSN: 2285 - 3065 
classical economics in which the decision-making is entirely based on rational behavior towards the behavioral economics which allows for irrational behavior.

Various researches have analyzed the role of people behavior in many economic decisions (Kahneman and Tversky, 2000; Collier, 2002; Thaler, 2008; Frey and Stutzer, 2012; Halla, 2010; Schneider and Klinglmair, 2004; Torgler and Schneider 2007). Regarding corruption, Collier (2002) argued that this phenomenon is an "extremely complex social behavior". Under these characteristics, Collier (2002) has developed an "interdisciplinary theory of the causes of corruption" starting from the use the institutional choice analytic frame. Nevertheless, the studies regards the behavioral determinant of corruption acts still need deepening and ideas about culture still seem useful in understanding how people recognize and respond to a corrupt behavior (Larmour, 2008).

This research comes to fill such a gap in behavioral economic literature of corruption by analyzing the influence of some behavioral factors provided by culture, tax morale, trust, religion or happiness on the level of corruption. A crosscountry survey of 148 countries was used. We found that power distance, trust in legal system, happiness and religion are the most important behavioral determinants of the corruption, explaining about $50 \%$ from the level of corruption around the world.

The paper is structure as follow. Section 1 focuses on the investigation of the research literature regards the relationship between the behavioral factors and the level of corruption. Section 2 describes the methodology and data used. Section 3 presents the results accompanied by related discussions. The paper ends with the conclusions which include a summary of the findings and a brief discussion of policy implications, limitations and avenues for future research.

\section{Literature review}

Starting from the study of Lewis (1978), one may found that people's attitudes, judgments and intentions are more affected by what they think than what they really are. Related to this, Kirchler (2007) provides broad explanations on taxpayers' economic psychology and how fiscal behavior is reflected through social representations of tax obligations and their link with individual, social, and societal attitudes and norms.

Social norms defined as the frecvency of missbehaving within a reference group are also very important for determining the corrupt behaviour. If a taxpayer feels that noncompliance is widespread and socially acceptable, then that taxpayer will most likely not comply (Wenzel 2005). According to Thaler and Sunstein (2008) people prefer instant gratification right now, even if they know that being patient would yield them more money or a better life down the road. Turning back to the

22 Sciendo Studia Universitatis "Vasile Goldis" Arad. Economics Series Vol 29 Issue 1/2019 ISSN: 1584-2339; (online) ISSN: 2285 - 3065

Web: publicatii.uvvg.ro/index.php/studiaeconomia. Pages $21-39$ 
culture of a people, Thaler and Sunstein's approach would be associated with the persistence of a short-term oriented culture in which immediate and not long-term benefits are valued. Following these studies, we may expect that various cultural and moral features such as long or short term orientation, the ability to do things in their own right, the way of avoiding uncertainties, honesty, trust in authorities, trust in people, pride, subjective-well being, relationship with nature and the world, and relationship with others may determine the individuals to accept immediate and illicit benefits instead of long and legal ones.

\subsection{Culture and corruption}

Various studies ((Husted, 1999; Davis and Ruhe, 2003; Tong, 2014; Achim, 2016) document a significant relationship between culture and coruption. For instance, Husted (1999), in his cross-country survey on 44 countries, finds that a higher power distance, higher masculinity and higher uncertainty avoidance are associated with higher corruption. Davis and Ruhe A. (2003), on their cross-countries analysis of 50 countries, also find that both power distance and masculinity come to explain a main variation of corruption's level. In addition, they also find out individualism as a determining factor for the level of corruption. Some similar results are obtained by Halkos and Tzeremes (2011) by using a sample consist of 77 countries. They also find that higher power distance and higher collectivism values are associated with a higher level of corruption but, as regards the masculinity, the results indicate a "U" shape relationship which is not statically significant. Following the cultural model of Hofstede, Achim (2016) also found that a higher power distance, a higher collectivism, and a lower term orientation increase the level of corruption. Regarding the collectivistic pattern, Tong (2014) explores the relationship between corruption and cultural psychology, by examining Chinese society. He finds that individual's negative experiences in childhood (e.g., poverty, hunger) along with a collectivist agrarian tradition is associated with a higher propensity towards the future corruption.

In their study, Fisman and Miguel (2007) found that diplomats from highly corrupt countries are more likely to violate parking law than diplomats from less corrupt countries and conclude that corruption is partially a cultural phenomenon. Similarly, the study of Barr and Serra (2010) found that among the undergraduates, which were classified by belonging to the most and the least corrupt countries, culture significantly influences corruption. Thus, they conclude that values and beliefs towards the corruption acts are strongly related to the host country.

Based on the evidences presented above we state the following hypothesis:

Hypothesis 1 Cultural factors come to affect the level of corruption 


\subsection{Tax morale and corruption}

Schmölders (1960) introduces the term of tax morale in relating to the feelings of civic and fiscal awareness among the citizens or taxpayers' and the intrinsic motivation to pay taxes. Regarding tax morale, tax behavior and corruption, Torgler (2007) reminds about these practices coming from Ancient Egypt. Here, the Pharaohs try to reduce the corruption among tax collectors which are called scribes, by giving high salaries to be less tempted to cheat on taxpayers.

Various studies (Schmölders, 1960; Torgler, 2007) reveal that, the more tax morale decreases the more individuals are less likely to respect the law and thus more inclined to cheat. Therefore, on the ground of lacking rule of law and accountability of the governance, the level of corruption increases (Abed and Gupta, 2002; Torgler, 2004). In this context, the countries with the highest tax morale, highest tax compliance level and the most stable economic environments without corruption practices are developed democratic ones. Although there are some evidences of the interaction between tax morale and corruption, we intend to obtain our evidence on this. Therefore, we state the following hypothesis:

Hypothesis 2 Increasing tax morale is associated with a lower propensity towards corruption

\subsection{Trust in governance and corruption}

A wide range of studies (Kirchler, 2007; Uslaner, 2002, 2013; Park and Blenkinsopp, 2011) highlight the importance of providing a high confidence in governance institutions in order to ensure the proper functioning of the state. Trust in government or public services reflect the citizens' subjective judgments based on their experience, in which they judge the government as being competent, reliable and honest when while also meeting their needs (Park and Blenkinsopp, 2011). A low trust in governance is associated with the identification of ways to circumvent the law (Kirchler, 2007). Therefore, trust influences institutional performance but also the institutional performance shapes the public's trust in their institutions and in one another (Uslaner, 2002; Morris and Klesner, 2010). The governance have a strong discretionary power over the allocation of resources and the bribes are paid to avoid paying taxes or following regulation (Torgler and Schneider, 2007) and thus trusting societies have less corruption.

Trust and corruption have different views about human nature, but they are complementary. Trust address an optimistic view on the world when trusters believe that world is a good place and they can make it better (Uslaner, 2002). Opposite, corruption is based upon a pessimistic and destructive view: "We rob

24 Sciendo Studia Universitatis "Vasile Goldis" Arad. Economics Series Vol 29 Issue 1/2019 ISSN: 1584-2339; (online) ISSN: 2285 - 3065

Web: publicatii.uvvg.ro/index.php/studiaeconomia. Pages $21-39$ 
Borlea, S.N., Achim, M.V., Rus, A.I.D., (2019)

Behavioral determinants of corruption. A cross-country survey

because we value creature comforts" (Uslaner, 2002). Consequently we assume the following working hypothesis:

Hypothesis 3 Increasing trust in governance determines a lower level of corruption

\subsection{Religion and corruption}

A first category of studies analyzes the relationship between religion and corruption starting from the features of each type of religions. Hierarchical religions such as Catholicism, Orthodox Christianity and Islam promote cultural attitudes associated with respect for social hierarchy and official authority (You and Khagram, 2005; Kilkon and Seong-Gin, 2014). At the opposite pole, there are individualistic religions such as Protestantism which promote economic freedom with a less involvement of government in the private sector. Therefore, these categories of religions are less tolerant with corruption acts than in those where hierarchical religions are dominant (Arvate et al., 2009; Kilkon and Seong-Gin, 2014).

A second category of studies investigates the relationship between religion and corruption starting from the level of religiosity. In this respect, a strand of studies (Faleye, 2013; North et al., 2013) documents that religion influence on the nation values, being responsible for the widespread corruption. The corruption in Nigeria (one of the most corrupt countries in the world) is mainly explained by the religion factors (Faleye, 2013). The three major religions in Nigeria are Christianity, Islam and African Traditional Religion. In his work, Faleye (2013) points out that the absence of Christian ethics in the educational curriculum represents the main cause of the widespread corruption in Nigeria. The author finds religion as being responsible for corruption in Nigeria and the way to combat it targets the religious leaders, which should be made accountable for the doctrines propagated by their organizations. Another study conducted by North et al. (2013) found similar results. Using a big database for 207 countries, with 23 different religious groups in the year 1900 and 2000, North et al. (2013) found that the level of corruption is lowest in the countries with Protestants and higher in the countries with Orthodox Christian.

Another strand of researches (Kilkon and Seong-Gin, 2014; Dreher et al., 2007; Shadabi, 2013) finds no relationship between religion and corruption. Making a big survey of 64 countries around the world, Kilkon and Seong-Gin (2014) find no support that believers in hierarchical religions are more obedient to authority than those in individualistic religions. In the study conducted over 100 countries, Dreher et al. (2007) find no significant effect of religion on the corruption. Shadabi (2013) investigates the effect of religion on corruption over 174 countries in 2010. They 
Borlea, S.N., Achim, M.V., Rus, A.I.D., (2019)

Behavioral determinants of corruption. A cross-country survey

document that religion (here Islam and Christianity) have no significant effect on corruption.

Based on the findings above, we conclude about existing the inconsistent results on the religion-corruption nexus. However, our assumption is that religion encourages high moral values of individuals that are incompatible with deception and theft. Rationally, we expect that religious believers to be more trustworthy and thus more likely to act honestly because they are guided by God's commitments in their lives (not to steal and to be morale. Thus, the following hypothesis is stated:

Hypothesis 4 Increasing the level of religiosity is associated with a lower propensity towards corruption

\subsection{Happiness and corruption}

The importance of focusing on mental well-being than material wealth and therefore measuring the nation's emotional prosperity rather than its economic prosperity is highlighted by Stiglitz et al. (2010). Under these approaches, Oswald (2010), a member of the Stiglitz Comission, argues that, by researching emotional prosperity, many behavioral acts in the economic filed will be better explained. For instance, Frey and Stutzern (2012) find that happiness has a major role on many important economic decisions such as working behavior, investment behavior, consumption activities and political behavior. Rothstein (2010) found that countries with low levels of corruption also face high levels of happiness and social wellbeing. Regarding the relation between happiness and corruption, we only find few studies (Rothstein, 2010; Arvin and Lew, 2012; Leon et al., 2013; Tay et al., 2014) which highlight the role of corruption on the level of human happiness and not vice-versa. Thus, we aim to cover such a gap in the literature by investigating the influence of happiness on corruption, under the following assumption:

Hypothesis 5 Increasing human happiness leads to a lower propensity towards corruption

\section{Methodology and data}

\subsection{Variables and data source}

The dependent variable consists in the level of corruption. The level of corruption is measured by Corruption Perceptions Index provided by Transparency International. This index measures the perceived levels of public sector corruption in 175 countries. Scores range from 0 (highly corrupt) to 100 (very clean). We deal with the rankings' countries range from 1 (lowest level of corruption) to 175 (highest level of corruption), for 2014. 
Borlea, S.N., Achim, M.V., Rus, A.I.D., (2019)

Behavioral determinants of corruption. A cross-country survey

The independent variables are represented by the folowing behavioral factors such as culture, tax morale, trust in governance, religion and hapiness. According to various studies (Mauro, 1995; Husted, 1999), wealth has a negative influence on the level of corruption. A high level of financial satisfaction conducts to a better comply with a low level may create the opportunity for the corruption's occurrence, as an expressions of the population's disagreement regarding the provision of public goods and insurance of welfare by the state. Thus, we will use wealth as controlling variable in the investigating the influence of behavioral factors on the level of corruption.

Culture is estimated with Hofstede's cultural model which comprises six cultural dimensions, as follow: Power distance - PD; Individualism versus collectivism IDV; Masculinity versus femininity - MAS; Uncertainty avoidance - UAI; Longterm orientation - UAI; Indulgence and restraint - IND. Each dimension places the culture of a nation on a scale from 0 to 100 . At the time of research, Hofstede's model is applied to 100 countries (The Hofstede Center, 2017).

In order to measure tax morale, we use data from World Values Survey covering the period 2005-2009 and 2010-2014 waves which ranking beliefs, values and motivations of people from for 78 countries. The survey question V201 Justifiable: Cheating on taxes if you have a chance is formulated as follow:

"Please tell me for each of the following statements whether you think it can always be justified, never be justified, or something in between: (...) Cheating on tax if you have the chance (\% never justified" with 1 point to "always" with 10 points, on a ten-points scale)."

The average values for each country are determined. They range between 1 point meaning lowest values to 4 points meaning highest value. The higher values, the higher propensity to cheating on taxes and therefore the lower level of tax morale.

To measure trust in governance we use data provided from World Values Survey, for 58 countries over the 2005-2009 and 2010-2014 waves. Measuring this trust, we are searching for answers to the three questions: V114 Confidence: The courts; V115 Confidence: The government (in your nation's capital); V117 Confidence: Parliament.

All three questions are formulated as follow:

"I am going to name a number of organizations. For each one, could you tell me how mисh you have in them: is it a great deal of confidence, quit a lot of confidence, not very much confidence or none at all: The government (in your nation's capital), The Courts, The Parliament."

For each dimension of governance an index is determined. It range between minimum -100 points meaning lowest index to 100 points meaning highest index. The higher values corespond to the higher level of trust in each components of 
governance. As regards the level of religiosity, we also use the WVS data, covering 79 countries surveyed on the 2005-2009 and 2010-2014 waves. We account for the reported answers to the question V9 Important in life: Religion, which is formulated as follow:

"For each of the following, indicate how important it is in your life. Would you say it is: very important, rather important; not very important, not all important. Religion."

An index measuring the importance of religion for each individuals are reported. It range from -100 meaning lowest index to 100 points meaning highest index. The higher score, the higher importance is religion for individuals belong to a specific country.

In order to measure human happiness we use data provided by The New Economics Foundation, according to the latest edition of "Happy Planet Index" (2012) (Abdallah et al.2012), which is determined for 151 countries. In our research we use the "subjective well-being" component of "Happy Planet Index" because the other two dimensions (life expectancy and foot print) could alter the subjective character of human happiness dimension. The score for "subjective well-being" varies from 0 to 10 (where 0 is the best life possible and 10 is the most undesirable life of an individual).

Wealth is determined by using a perception of individuals on the financial situation of theirs household. We use data from World Values Survey, 2005-2009 and 20102014 waves for 79 countries are used, by answering to the question V59 Satisfaction with financial situation of households following:

"How satisfied are you with the financial situation of your household? "Completely dissatisfied" with 1 point to "Completely satisfied" with 10 points, on a ten-points scale)."

The average values for this question for every country are reported. The average values range from 4 (the lowest mean) to 8.7 (the highest mean). The higher average score goes for the higher level of financial satisfaction of household.

\subsection{Method}

The first step is to test the aforementioned working hypotheses in order to identify the impact of the subjective factors namely culture, tax morale, trust in governance, religion and hapiness, on the level of corruption. A simple linear regression analysis are used along with correlation coefficients and ANOVA. Further, these results are used in a second stage to create a model for estimating the level of corruption as a function of subjective factors. The multiple linear regression analysis are used. All the necessary validation procedures are performed to ensure statistical significance of the results.

28 Sciendo Studia Universitatis "Vasile Goldis" Arad. Economics Series Vol 29 Issue 1/2019 ISSN: 1584-2339; (online) ISSN: 2285 - 3065

Web: publicatii.uvvg.ro/index.php/studiaeconomia. Pages $21-39$ 
Borlea, S.N., Achim, M.V., Rus, A.I.D., (2019)

Behavioral determinants of corruption. A cross-country survey

To test whether moral or behavioral values of individuals foster a lower level of corruption, after controlling for financial satisfaction (wealth), the baseline equation is stated, as follow:

COR $_{\mathrm{i}}=\alpha+\beta_{1}$ CULT $_{\mathrm{i}}+\beta_{2}$ TAXM $_{\mathrm{i}}++\beta_{4}$ TRUST $_{\mathrm{i}}++\beta_{5}$ RELIG $_{\mathrm{i}}+\beta_{6}$ HAPPY $_{\mathrm{i}}+\beta_{3}$ WEALTH $_{\mathrm{i}}+\varepsilon_{\mathrm{i}}$

(1) Where:

$\mathrm{i}$ indexes the countries in the sample; $\mathrm{COR}_{\mathrm{i}}$ is the level of coruption; $\mathrm{CULT}_{i}$ is the index of culture determined with the Hofstede six dimensions (PD, IDV, MAS, UAI, LTO, IND); TAXM $\mathrm{i}_{\mathrm{i}}$ is the level of tax morale measured by bheating on taxes (Cheat); TRUST $_{\mathrm{i}}$ is the level of trust or confidence in the court (Conf_Court), trust in the government (Conf_Gov) and in the Parliament (Conf_Parl); RELIG $\mathrm{G}_{\mathrm{i}}$ reflects the degree of religiosity, measure by how important in life is religion (RELIG); HAPPY $_{i}$ is the level of happiness determined as feeling happiness measured as subjective well-being (HAPPY); $\mathrm{WEALTH}_{\mathrm{i}}$ is the perception of financial situation household measured by Financial satisfaction (WEALTH); $\varepsilon_{i t}$ is the regression error.

\section{Results and discussions}

Table 1 shows the pairwise Pearson correlations between the variables. One may found that the higher correlations were found between corruption and three dimensions of culture (PD, IDV and LTO), well-being, religion, wealth and trust in court. We also see high correlations between PD and IDV $(r=-0.656)$, PD and religion ( $\mathrm{r}=0.559)$, IDV and religion $(\mathrm{r}=0.518)$, well-being and wealth. The high correlations between these variables are taken in account later, to not affect the assumptions of OLS regression.

Table 1 Pearson correlations

\begin{tabular}{|l|r|r|r|r|r|r|r|r|r|r|r|r|}
\hline & \multicolumn{1}{c|}{ COR } & \multicolumn{1}{c|}{ PD } & \multicolumn{1}{c|}{ IDV } & MAS & \multicolumn{1}{c|}{ UAI } & \multicolumn{1}{c|}{ LTO } & IND & TAXM & CONF & RELIG & WB & WEALTH \\
\hline COR & 1 & & & & & & & & & & & \\
\hline PD & $.585^{* *}$ & 1 & & & & & & & & & & \\
\hline IDV & $-.613^{* *}$ & $-.656^{* *}$ & 1 & & & & & & & & & \\
\hline MAS & .162 & .110 & .051 & 1 & & & & & & & & \\
\hline UAI & .048 & .148 & -.119 & .047 & 1 & & & & & & & \\
\hline LTO & $-.344^{* *}$ & -.121 & $.269^{*}$ & .081 & .100 & 1 & & & & & & \\
\hline IND & -.165 & $-.246^{*}$ & .092 & -.094 & -.198 & $-.463^{* *}$ & 1 & & & & & \\
\hline TAXM & .226 & .257 & .107 & .043 & -.216 & .036 & -.167 & 1 & & & & \\
\hline Conf_Curt & $-.344^{* *}$ & -.049 & .177 & .031 & $-.570^{* *}$ & $.366^{*}$ & -.116 & .052 & 1 & & & \\
\hline RELIG & $.512^{* *}$ & $.559^{* *}$ & $-.518^{* *}$ & .157 & .094 & $-.599^{* *}$ & -.026 & .155 & -.110 & & & \\
\hline HAPPY & $-.566^{* *}$ & $-.484^{* *}$ & $.434^{* *}$ & .007 & .057 & .125 & $.541^{* *}$ & -.156 & .109 & $-.468^{* *}$ & 1 & \\
\hline WEALTH & $-.409^{* *}$ & $-.334^{*}$ & $.260^{*}$ & -.060 & -.215 & .021 & $.500^{* *}$ & -.116 & .223 & -.213 & $.678^{* *}$ & \\
\hline
\end{tabular}

** Correlation is significant at the 0.01 level (2-tailed)

* Correlation is significant at the 0.05 level (2-tailed)

Source: author's view 
Borlea, S.N., Achim, M.V., Rus, A.I.D., (2019)

Behavioral determinants of corruption. A cross-country survey

Table 2 shows the descriptive statistics and results of the linear regression analysis, when corruption is a dependent variable and culture, tax morale, trust in governance, religion, happiness and wealth are independent variables, taking one by one.

Table 2 Descriptive statistics and results of simple regression analysis

\begin{tabular}{|c|c|c|c|c|c|c|}
\hline Variables & Mean & $\begin{array}{c}\text { St. } \\
\text { Dev. }\end{array}$ & $\begin{array}{l}\text { Regr } \\
\text { Coef. }\end{array}$ & Std err. & t-stat & $\begin{array}{l}\text { Sig. } \\
\text { (regr. } \\
\text { coef) }\end{array}$ \\
\hline \multicolumn{7}{|c|}{ Dependent variable } \\
\hline Corruption & 78.01 & 47.371 & & & & \\
\hline \multicolumn{7}{|c|}{ Independent variables } \\
\hline \multicolumn{7}{|l|}{ 1. Culture } \\
\hline $\mathrm{PD}$ & 64.06 & 20.828 & 0.792 & 0.273 & 2.902 & 0.005 \\
\hline IDV & 39.22 & 22.048 & -0.551 & 0.243 & -2.268 & 0.026 \\
\hline MAS & 47.65 & 18.647 & 0.304 & 0.195 & 1.560 & 0.123 \\
\hline UAI & 63.86 & 21.417 & -0.058 & 0.177 & -0.326 & 0.745 \\
\hline LTO & 41.75 & 22.897 & -0.655 & 0.189 & -3.475 & 0.001 \\
\hline IND & 48.22 & 22.907 & -0.406 & 0.194 & -2.100 & 0.039 \\
\hline
\end{tabular}

Regression equation characteristics:

$\begin{array}{llll}\text { Adjusted R Square }=0.52 & F=14.889 & \text { sig. }(\text { ANOVA })=0.000 \quad N=77\end{array}$

2. Tax morale

\begin{tabular}{|l|l|l|l|l|l|l|}
\hline TAXM & 2.1179 & 0.80158 & 16.687 & 46.832 & 1.997 & 0.049 \\
\hline
\end{tabular}

Regression equation characteristics:

Adjusted R Square $=0.038 \quad F=3.988 \quad$ sig. $($ ANOVA $)=0.049 \quad \mathrm{~N}=77$

3. Trust in governance

\begin{tabular}{|l|r|r|r|r|r|r|}
\hline Conf_Court & 9.9655 & 36.709 & -0.861 & 0.218 & -3.956 & 0.000 \\
\hline Conf_Gov & -5.71 & 36.876 & 0.737 & 0.396 & 1.863 & 0.068 \\
\hline Conf_Parl & -19.45 & 39.624 & -0.141 & 0.378 & -0.374 & 0.710 \\
\hline
\end{tabular}

Regression equation characteristics:

Adjusted R Square $=0.199 \mathrm{~F}=5.733$ sig. $($ ANOVA $)=0.002 \mathrm{~N}=57$

\section{Religion}

\begin{tabular}{|l|r|r|r|r|r|r|}
\hline RELIG & 41.37 & 51.419 & 0.473 & 0.092 & 5.159 & 0.000 \\
\hline
\end{tabular}

Regression equation characteristics:

Adjusted R Square $=0.52 \quad F=26.612$ sig. $($ ANOVA $)=0.000 \mathrm{~N}=76$

5. Happiness

\begin{tabular}{|l|r|r|r|r|r|r|}
\hline HAPPY & 5.4410 & 1.327 & -23.64 & 3.04 & -7.75 & 0.000 \\
\hline
\end{tabular}

Regression equation characteristics:

Adjusted R Square $=0.315 \mathrm{~F}=60.197$ sig. $($ ANOVA $)=0.000 \mathrm{~N}=129$

\section{Wealth}

\begin{tabular}{|l|r|r|r|r|r|r|}
\hline WEALTH & 5.7810 & 1.272 & -22.386 & 5.766 & -3.883 & 0.000 \\
\hline
\end{tabular}

Regression equation characteristics:

Adjusted R Square $=0.156 \quad \mathrm{~F}=15.074 \quad$ sig. $($ ANOVA) $=0.000 \quad \mathrm{~N}=76$

* denotes significant at 10\% level, ** significant at 5\% level, ***significant at $1 \%$ level

Source: author's view 
Borlea, S.N., Achim, M.V., Rus, A.I.D., (2019)

Behavioral determinants of corruption. A cross-country survey

Table 3 reflects the models of corruption resulted from the running of the statistical tests. The multivariate regression analysis is applied by using the most significance variables which were found in the statistical tests conducted before. Analyzing many other combinations of variables, we get the most significance models, as they are presented in table 3 .

Table 3 Multiply regression analysis of corruption. Regression coefficients

\begin{tabular}{|c|c|c|c|c|c|}
\hline Variables & Model 1 & Model 2 & Model 3 & Model 4 & Model 5 \\
\hline PD & $0.637 *$ & & $.720 * * *$ & & \\
\hline IDV & & -.276 & & $-.497 * *$ & -.382 \\
\hline \multicolumn{6}{|l|}{ LTO } \\
\hline TAXM & & & & & 11.558 \\
\hline Conf_Court & $-.402 * *$ & $-.378 * * *$ & & & $-.395 * * *$ \\
\hline RELIG & $0.206^{*}$ & $0.248 * *$ & $0.247 * * *$ & $0.261 * * *$ & $0.222 * *$ \\
\hline HAPPY & $-15.122 * *$ & $-18.692 * * *$ & $-13.530^{* * *}$ & $-15.020 * * *$ & $-16.31 * *$ \\
\hline $\mathbf{F}$ & 12.663 & 11.293 & 22.164 & 21.325 & 8.828 \\
\hline Adj. R square & 0.538 & 0.507 & 0.531 & 0.521 & 0.501 \\
\hline Anova (Sig.) & 0.000 & 0.000 & 0.000 & 0.000 & 0.000 \\
\hline Variables & Model 6 & Model 7 & Model8 & Model 9 & \\
\hline PD & & 0.583 & & & \\
\hline \multicolumn{6}{|l|}{ IDV } \\
\hline LTO & -.054 & & .203 & .169 & \\
\hline TAXM & & 5.570 & & 7.035 & \\
\hline Conf_Court & & $-.418 * * *$ & $-.419 * * *$ & $-.419 * * *$ & \\
\hline RELIG & $0.277 * *$ & $0.208^{*}$ & $0.308^{* *}$ & $0.293^{*}$ & \\
\hline HAPPY & $-21.373 * * *$ & $-14.851 * *$ & $-21.978 * * *$ & $-20.617 * * *$ & \\
\hline $\mathbf{F}$ & 16.787 & 9.197 & 10.147 & 7.454 & \\
\hline Adj. R square & 0.481 & 0.512 & 0.497 & 0.473 & \\
\hline Anova (Sig.) & 0.000 & 0.000 & 0.000 & 0.000 & \\
\hline
\end{tabular}

$*$ denotes significant at $10 \%$ level, ** significant at $5 \%$ level, ***significant at $1 \%$ level Source: author's view

The hypothesis 1 examines whether the culture may influence the level of the corruption. The data used consist in sample of countries for which both data for Hofstede's culture dimensions and the level of corruption are available. This resulted in a sample of 77 countries. Table 2 shows that culture expressed by Hofstede model helps in explaining more than a half $($ Adj. R Square $=0.52)$ of the 
level of corruption, around the world countries, at a significance level of $1 \%$ (sig. $($ ANOVA $)=0.000)$. Therefore the hypothesis $\mathrm{H} 1$ is accepted.

Table 1 and 2 show that power distance (PD), individualism-collectivism (IDV) and long-versus short-term orientation (LTO) are found the cultural dimensions of corruption which highly influence on the level of corruption.

A higher power distance is found associated with a higher level of corruption. This is a hierarchical society in which superiors provide favors to subordinates in returns for their loyalty and the corruption may occur under the forms of nepotism and favoritism (Husted 1999). The results are similar with those of Davis and Ruhe (2003) and Tong (2014) who also find a positive correlation between power distance and corruption. The influence of individualism-collectivism (IDV) and long-versus short-term orientation (LTO) on the level of corruption are negative and statistically significant. Therefore, a higher individualism (a less collectivism) conducts to a lower level of corruption. In a collectivistic society the groups of family and friends create incentive to violate the law in order to meet their own ingroups interests. These results are also supported by other researches of Halkos and Tzeremes (2011) and Tong (2014). A higher long-term orientation (a lower short-term orientation) diminishes the level of corruption. Therefore, under a short-term orientation culture the individuals are concerned on achieving quick results and asking or giving a bribe may occurs.

However, the multivariate analysis presented in table 3 retains in the final model of corruption only the power distance dimension of culture, as being the highest and significant cultural factor that influences on the level of corruption. As North et al. (2013) note, the effects of some control variables may distort the influences of factors on the level of corruption.

Hypothesis 2 investigates the relationship between tax morale and corruption. The final sample data consists in 77 countries, for which both data of tax morale and the level of corruption are available. The average of cheating on taxes in sample is 2.11, on a scale between 1 to 4 (from the lowest level to the highest level of cheating). A positive correlation are found between cheating on taxes and corruption $(\mathrm{r}=0.226)$, meaning that a higher propensity to cheating on taxes (or the lower level of tax morale) are associated with a higher level of corruption. The Pearson correlation is significance at a level of significance of 5\%. Going to the linear regression analysis, the variation of corruption is explaining by the cheating on taxes only in a percent of $3.8 \%$. But, the regression coefficient is also found positive and statistically significant at $5 \%$ level of significance, meaning that increasing cheating on taxes (decreasing tax morale) may conduct to a higher propensity towards corruption. However, the multivariate analysis presented in

32 S sciendo Studia Universitatis "Vasile Goldis" Arad. Economics Series Vol 29 Issue 1/2019 ISSN: 1584-2339; (online) ISSN: 2285 - 3065

Web: publicatii.uvvg.ro/index.php/studiaeconomia. Pages $21-39$ 
table 3 rejects the tax morale from the model, when many other variables are also considered. In these circumstances, the hypothesis 2 cannot be accepted.

Hypothesis 3 examines the relationship between trust and corruption. Both data on trust and corruption are available for 57 countries. The results point out that trust in governance, measured as trust in the court, in the government and in the parliament, has a strong impact on the level of corruption. The higher trust in governance determines a lower level of corruption, and this relationship is statistically significant at a level of significance of $1 \%$ (sig.ANOVA=0.002), supporting the hypothesis 3 (table 2). About $20 \%$ from the variation of the level of corruption is explained by the level of trust in governance (Adj. R square $=0.199$ ). Analyzing these three estimators of trust in governance (trust in the court, in the government and in the parliament), we find out that trust in legal system is the most important dimension of trust. Only for this dimension of trust, both the correlation and the regression coefficients are statistically significant, at a level of significance of $1 \%$. Moreover, our multivariate analysis retains trust in legal system as significant and negative predictors for the level of corruption. The higher the legal system, the lower the level of corruption, thus supports our hypothesis 3 . These findings are in line with the results of Uslaner (2002), Torgler (2007), Graeff and Svendsen (2013), who also find trust determining the level of corruption. In this respect, Kramer (1999) considers that the efficiency of the state, and especially of the tax authorities, depends on individuals' feelings of commitment to the community, the willingness to comply with regulations and the willingness to voluntarily comply with the authorities. If the authorities should always explain and justify their actions, their work to coordinate public services would be considerably diminished (Kirchler, 2007). Thus, trust is an important factor in understanding the sources of civic engagement in co-operation with authorities and compliance.

Hypothesis 4 looks after some relationship between religion and corruption. The analysis is conducted over 76 countries for which both data on religion and corruption are available. The results of Pearson correlation $(\mathrm{r}=0.512)$ and the linear regression analysis point out a positive relationship between religion and corruption which is statistical significant (table 1 and table 2). More than a half of the level of corruption is explained by the religion of the individuals (Adj. R square $=0.52$ ). Our findings contradict the stated hypothesis 4 , thereby it is rejected. We even find the opposite results. If the level of religiosity increases, the level of corruption increases as well. Thus this findings are statistical significant at $1 \%$ level of significance (sig. $($ ANOVA $)=0.000)$. In addition, our multivariate analysis conducted in tables 3 strengthens this result. The influence of religion is a very good predictor of the level of corruption no matter of the controlling variables 
is used. The religion' coefficients are statistical significant and positive in all the nine models presented in table 3 .

Thus, our findings clearly enhance a significant role of religion on the level of corruption, even the sign is not the expected one. The basic assumption is that religious believers to be more trustworthy and thus more likely to act honestly because they are guided by God's commitments in their lives. Therefore, we expect that religion encourages high moral values of individuals. However, our evidence reflects the opposite. When we analytically check distribution of data across countries, indeed we see the least corrupt countries in the world (namely Denmark, New Zeeland, Sweden, Finland and Norway) have also a lowest level of religiosity. In these countries about $30-35 \%$ of the people consider that religion is very or rather important in their lives. Opposite, a high level of religiosity (about 96-98\%) are found in the most corrupt countries in the world (namely Nigeria, Algeria, Philippines, and Egypt). In Europe, Romania and Italy are two of the most corrupt countries which also face simultaneously high level of religiosity of about $80 \%$. Similar empirical findings are revealed by Faleye (2013) for the case of Nigeria, who find that a high religiosity is associated with a high level of corruption. $\mathrm{He}$ explains this paradox by the fact that Nigerian people appears to be emotional or spiritual satisfied from being religious and committing oneself to a corrupt lifestyle and living.

Hypothesis 5 tests the relationship between happiness and corruption. We found a significant and negative influence of happiness on the corruption which comes to explain $31.5 \%$ from the variation of the corruption. The bivariate correlation coefficient comes to support a negative and significant correlation between happiness and corruption ( $\mathrm{r}=-0.566)$ (table 1). Multivariate analysis of corruption presented in table 3, retain happiness as being among the most significant predictors of corruption, along the other variables. Thus, one may conclude that the level of human happiness reduces the incentives for corruption acts, thus supporting our hypothesis 5 . Some similarly studies indirectly come to supports these findings. For example, Schneider and Klinglmair (2004) and Halla (2010) found that happiness influences on the shadow economy. On the other hand, shadow economy and corruption are interrelated (Dreher and Schneider, 2006). To our knowledge, we have not identified in literature any study investigating the influence of happiness or subjective well-being on the level of corruption. Thus, our findings come to fill such a gap in the literature on the happiness-corruption nexus.

To synthesis our findings, we may conclude that power distance, trust in legal system, happiness and religion are found among the highest behavioral predictors

34 S sciendo Studia Universitatis "Vasile Goldis" Arad. Economics Series Vol 29 Issue 1/2019 ISSN: 1584-2339; (online) ISSN: 2285 - 3065

Web: publicatii.uvvg.ro/index.php/studiaeconomia. Pages $21-39$ 
Borlea, S.N., Achim, M.V., Rus, A.I.D., (2019)

Behavioral determinants of corruption. A cross-country survey

of corruption, explaining about 50\% from the level of corruption around the world (models 1 and 3).

\section{Conclusions}

Recent studies document that many economic acts are better explained by investigating the behavioral factors such as long or short term orientation, the ability to do things in their own right, the way of avoiding uncertainties, honesty, trust in authorities, trust in people, pride etc. This research comes to empirical investigate whether the country's levels corruption may be explained by some behavioral factors such as culture, tax morale, trust, religion or happiness. Unlike other studies, our research has as main element of originality putting together, beside culture, other behavioral factors such as tax morale, trust, religion or happiness. A cross-countries survey of 148 countries is used, over a whole period of 2005-2014.

Our findings point out that among the cultural factors, power distance has the highest and significant influence on the level of corruption. Power distance along with the other three variables namely trust in legal system, happiness and religion are found to be the most important behavioral determinants of the corruption, explaining more than a half of the country's levels corruption around the world countries. A higher power distance, a lower level of trust in legal system and a lower level of happiness (measure by subjective well-being) conduct to a higher level of corruption, which confirm our expectations. A higher power distance culture is a hierarchical society characterizes by nepotism and favoritism in which superiors provide some favors to subordinates in returns for their loyalty. A lower level of trust in legal system erodes the civic engagements in cooperation with authorities and compliances, and it incentives people to get immediate benefits instead to wait the future and get uncertain public goods. In addition, happier people are more likely to act honestly thus the level of corruption decreases.

In addition, a higher level of religiosity is found to be associated with a higher level of corruption. Thus, in the poor countries facing the highest level of corruptions, people plenty suffer of poverty, unemployment and insecurity thereby a corrupt life style emerges. Further, they feel the need to feed their dishonesty and sins with religion, thus becoming emotional or spiritual satisfied.

Our research suggests that behavioral factors may help to explain the level of corruption from a country. The findings may have significant social implications for policy-makers who are seeking for ways of reducing the level of corruption in order to safeguard the national economy. The governments have to acknowledge the role of the behavioral factors and this way may adopt the most appropriate decisions to fight against the corruption. 
We acknowledge some limits of our research as being represented by not using some determinant factors such as sex, type of religion, education etc. In future works, we have in mind to complete our analysis by adding other behavioral factors, in order to substantiate our findings.

\section{Acknowledgements}

The authors thank the anonymous reviewers and editor for their valuable contribution.

\section{Funding}

This research received no specific grant from any funding agency in the public, commercial, or not - for - profit sectors.

\section{Authors Contributions}

MVA is responsible for the topic of research, performing the statistical methodology, compilation of the statistical and economical interpretation of the results, language and the general overview. SNB is responsible for making the literature review, assessing the hypotheses and economical interpretation of results, and assessing the economic conclusions. AIDR is responsible for the compilation of the statistical and economical interpretation of the results and assessing the economic conclusions.

\section{Disclosure Statement}

The authors have not any competing financial, professional, or personal interests from other parties.

\section{References}

1. Abdallah, S., Michaelson, J., Shah, S., Stoll, L., Marks, N. (2012), The Happy Planet Index: 2012 Report. A global index of sustainable well-being (nef: London).

2. Abed, G.T., Gupta, S. (2002), Governance, Corruption, \& Economic Performance, International Monetary Fund, September 23.

3. Achim, M. (2016), Cultural Dimension of Corruption: A Cross-Country Survey, Intenational Advance,, Economic Research (2016) 22:333-345

4. Arvate, P.R., Curi, A.Z., Rocha, F., Miessi, S.F. (2009), Corruption and the size of government: Causality tests for OECD and Latin American countries, Applied Economics Letters, 17(10), 1013-1017.

5. Arvin, M.B., Lew, B. (2012), Development aid, corruption and the happiness of nations: analysis of 118 countries over the years 1996-2009, Applied Econometrics and International Development 12(2), 69-78.

36 S sciendo Studia Universitatis "Vasile Goldis" Arad. Economics Series Vol 29 Issue 1/2019 ISSN: 1584-2339; (online) ISSN: 2285 - 3065

Web: publicatii.uvvg.ro/index.php/studiaeconomia. Pages $21-39$ 
6. Barr, A., Serra, D. (2010). Corruption and culture: an experimental analysis. Journal of Public Economics, 94, 862-869.

7. Bock, S.J., Salmon, B.E. (2017), Anti-Bribery and Corruption Benchmarking Report, Beyond Regulatory Enforcement. The Rise of Reputational Risk, available at https://www.kroll.com/en-us/abc-report accessed at October 20 2018.

8. Caselli, F., Michaels, G. (2013), Do Oil Windfalls Improve Living Standards? Evidence from Brazil, American Economic Journal: Applied Economics 5(1), 208-238.

9. Collier, M.W. (2002), Explaining corruption: An institutional choice approach, Crime, Law and Social Change, 38(1), 1-32.

10. Davis, J.H., Ruhe, D.J.A. (2003), Perceptions of country corruption: antecedents and outcomes, Journal of Business Ethics, 43(4), 275-288.

11. Dreher, A., Kotsogiannis, C., McCorriston, S. (2007), Corruption around the world: Evidence from a structural model, Journal of comparative economics, 35: 443-466.

12. Dreher, A., Schneider, F. (2006), Corruption and the Shadoweconomy. An empirical analysis, working paper 2006, CREMA Gellerstrasse 24-CH-4052.

13. Faleye, O.A. (2013), Religion corruption: a dilemma of the Nigerian state, Journal of Sustainable Development in Africa, 15(1), 170-185.

14. Frey, B. S., Stutzer A. (2012), The Use of Happiness Research for Public Policy, Social Choice and Welfare, 38 (4), 659-674.

15. Halla, M. (2010), The link between the intrinsic motivation to comply and compliance behavior: a critical appraisal of existing evidence, IZA Discussion Paper.

16. Halkos, G., Tzeremes, N. (2011), Investigating the cultural patterns of corruption: A nonparametric analysis, MPRA Munich Personal RePEc Archive.

17. Fisman, R., Miguel, E. (2007). Corruption, norms, and legal enforcement: evidence from diplomatic parking tickets. Journal of Political Economy, 115(6), 1020-1048.

18. Frey, B.S., Stutzer, A. (2012), The Use of Happiness Research for Public Policy, Social Choice and Welfare, 38 (4), 659-674.

19. Graeff, P., Svendsen, G.T. (2013), Trust and corruption: The influence of positiveand negative social capital on the economic development in the European Union, Quality \& Quantity, 47, 2829-2846.

20. Hofstede, G. (2011), Dimensionalizing Cultures: The Hofstede Model in Context. Online Readings in Psychology and Culture, 2(1). http://dx.doi.org/10.9707/2307-0919.1014. 
21. Hofstede, G. (1997), Cultures and Organizations: Software of the Mind, Mc. Graw Hill Publishing, New York.

22. Hofstede Center, 2017, available at http://geert-hofstede.com/, accessed on October 2017.

23. Husted, B.W. (1999), Wealth, Culture, and Corruption, Journal of International Business Studies, 30(2), 339-59.

24. Larmour, P. (2008), Corruption and the concept of 'Culture': Evidence from the Pacific Islands, Crime Law and Social Change, 49(3), 225-239.

25. Lewis, A. (1978) Perception of tax rate. British tax revue, 5, 358-366.

26. Kahneman, D., Tversky, A. (Eds.) (2000), Choices, Values and Frames. New York: Cambridge University Press.

27. Kilkon, K, Seong-Gin, M. (2014), The relationship between religion and corruption: are the proposed causal links empirically valid? International Review of Public Administration, 19(1), 44-62, DOI: 10.1080/12294659.2014.887353.

28. Kirchler, E. (2007), The Economic Psychology of Tax Behavior. Cambridge University Press, Cambridge, England.

29. Kramer, R.M. (1999), Trust and distrust in organizations: emerging perspectives, enduring questions. Annual Review of Psychology, 50(1), 569598.

30. Kroll (2015), Anti-Bribery and Corruption (ABC) Benchmarking Report, available at http://www.kroll.com, accessed on October 2015.

31. Leon, C.J., Aran, J.E., Leon, J. (2013), Valuing the social cost of corruption using subjective well being dataand the technique of vignettes, Applied Economics, 45:3863-3870.

32. Mauro, P. (1995), Corruption and Growth, The Quarterly Journal of Economics, 110 (3), 681-712.

33. Morris, S.D., Klesner, J.L. (2010), Corruption and Trust: Theoretical Considerations and Evidence from Mexico, Comparative Political Studies, 43(10), 1258- 1285.

34. North, C.M., Orman W.H., Gwin C.R. (2013), Religion, Corruption, and the Rule of Law, Journal of Money, Credit and Banking, 45 (5), 757-779.

35. Oswald, A.J. (2010), Emotional Prosperity and the Stiglitz Commission. IZA Discussion Paper No. 5390, December.

36. Park, H., Blenkinsopp, J. (2011), The roles of transparency and trust in the relationship between corruption and citizen satisfaction, International Review of Administrative Sciences, 77(2), 254-274.

37. Rothstein, B. (2010), Corruption, Happiness, Social Trust and the Welfare State: A Causal Mechanisms Approach, QoG Working Paper Series 2010, 1-24

38 Sciendo Studia Universitatis "Vasile Goldis" Arad. Economics Series Vol 29 Issue 1/2019 ISSN: 1584-2339; (online) ISSN: 2285 - 3065

Web: publicatii.uvvg.ro/index.php/studiaeconomia. Pages $21-39$ 
available at http://qog.pol.gu.se/digitalAssets/1350/1350166_2010_9_rothstein. pdf, accessed on October 2017.

38. Shadabi, L. (2013), The Impact of Religion on Corruption, The Journal of Business Inquiry 12, 102-117.

39. Schmölders, G. (1960), Fiscal psychology: A new branch of public finance, National Tax Journal, 12, 340-345.

40. Schneider, F., Klinglmair, R. (2004), Shadow economies around the world: what do we know? Universität Linz, Working Paper No. 0403.

41. Stiglitz, J. E., Sen, A., Fitoussi, J.P. (2010), Mismeasuring Our Lives: Why GDP Doesn't Add Up, Commission on the Measurement of Economic Performance and Social Progress, New Press.

42. Tay, L.H., Mitchel, N., Diener, Ed. (2014), Detrimental Effects of Corruption and Subjective Well-Being: Whether, How and When, Social Psychological and Personality Science 5(7), 751-759.

43. Thaler, R.H, Sunstein, C.R. (2008) Nudge: Improving Decisions about Health, Wealth, and Happiness, Yale University Press,

44. Tong, W. (2014), Analysis of Corruption from Sociocultural Perspectives, International Journal of Business and Social Science, 5, 11(1), 9-19.

45. Torgler, B., Schneider, F. (2007), The Impact of Tax Morale and Institutional Quality on the Shadow Economy, IZA Discussion Paper.

46. Torgler, B. (2007), Tax Compliance and Tax Morale: A Theoretical and Empirical Analysis. Edward Elgar Publishing, 2007.

47. Transparency International. 2015. Corruption perception index. /www.transparency.org/research/cpi/ (accessed October 20, 2015).

48. Uslaner, E.M. (2013), Trust and corruption revisited: how and why trust and corruption shape each other, Quality and Quantity 47, 3603-3608.

49. Uslaner, E.M. (2002), Trust and Corruption, American Political Science Association, http://citeseerx.ist.psu.edu/viewdoc/download?doi=10.1.1.568.9243\&rep=rep1 \&type=pdf, accessed on October 2017.

50. You, J.S., Khagram, S. (2005), A comparative study of inequality and corruption. American Sociological Review, 70(1), 136-157.

51. World Values Survey, available at http://www.worldvaluessurvey.org/, accessed on October 2017.

52. Wenzel, M. (2005), Misperceptions of social norms about tax compliance: From theory to intervention. Journal of Economic Psychology, 26(6), 862-883. 